Revista de Dialectología y Tradiciones Populares, vol. LXXIII, n. ${ }^{\circ}$ 2, pp. 325-341, julio-diciembre 2018,

ISSN: 0034-7981, eISSN: 1988-8457,

https://doi.org/10.3989/rdtp.2018.02.003

\title{
ARTÍCULOS
}

\section{Relatos de vidas en la pobreza. Estrategias individuales de usuarios de la Renta Mínima de Inserción}

\author{
Stories of Lives in Poverty. Individual Strategies \\ of users of "Minimum Income of Insertion"
}

\author{
Francisco Estepa Maestre ${ }^{1}$ \\ Universidad de Cádiz \\ Beltrán Roca Martínez ${ }^{2}$ \\ Universidad de Cádiz
}

\section{RESUMEN}

El artículo estudia las diferentes estrategias de usuarios de las Rentas Mínimas de Inserción en España a partir de una revisión de la perspectiva teórica de la acumulación de activos, desarrollada para el estudio de las dinámicas de pobreza y exclusión en otros contextos. Para tal fin, se utilizan tres relatos de vida seleccionados de una muestra más amplia. A partir del análisis de las narraciones biográficas de los sujetos se construye una tipología de estrategias económicas individuales con base en los tipos de activos movilizados.

Palabras clave: Historia de vida; Salario social; Renta Mínima de Inserción; Pobreza; Estrategia.

\section{SUMMARY}

The article studies the different strategies of users of the 'Minimum Income of Insertion' in Spain from a review of the theoretical perspective of assets accumulation, developed for the study of the dynamics of poverty and exclusion in other contexts. For this purpose, three life stories are used that have been selected from a larger sample. From the analysis of the biographical narratives of the subjects, a typology of individual economic strategies is constructed based on the type of assets mobilised.

Keywords: Life History; Social Wage; Minimum Income of Insertion; Poverty; Strategy.

\footnotetext{
${ }^{1}$ Correo electrónico: Francisco.estepa@uca.es. ORCID iD: <https://orcid.org/0000-0002-7130-041X>.

${ }^{2}$ Correo electrónico: Beltran.roca@uca.es. ORCID iD: <https://orcid.org/0000-0001-5534-7843>.
} 


\section{INTRODUCCIÓN}

Este artículo tiene como objetivo estudiar la diversidad de estrategias individuales de los usuarios de la Renta Mínima de Inserción (RMI) para hacer frente a la situación de pobreza. Las RMI, son prestaciones económicas concebidas para que ningún ciudadano se quede sin nada para vivir, por lo que marcan un nivel mínimo de la protección social ${ }^{3}$. Se integraron en los Servicios Sociales en España en la década de 1980 y se implantaron en Andalucía el 23 de febrero de 1990 a través del Decreto 400/1990 (que fue modificado y mejorado posteriormente por el Decreto 2/1999). El objetivo inicial de esta medida era "la erradicación de la marginación y la desigualdad en Andalucía". La filosofía de este programa tenía un fuerte componente de inclusión social, tratando de ir más allá de acciones meramente asistenciales. Se concibió desde un principio como algo más que un simple salario social. Para ello se tomaron una serie de decisiones fundamentales con el fin de orientar la política social en esta dirección.

Este subsidio, según la normativa de la Comunidad Autónoma de Andalucía, asciende en el año 2017 a una cuantía de 400,09 euros mensuales, incrementándose en 51,62 euros al mes por miembro de unidad familiar hasta un máximo de 645,30 euros. El disfrute de la prestación tiene una duración máxima de 6 meses. Además, para poder solicitarla es necesario: estar empadronado en Andalucía con un mínimo de un año de antigüedad; carecer de recursos económicos suficientes para las necesidades básicas de la vida; haber solicitado todas otras ayudas públicas, es decir, prestaciones o pensiones que le pudieran corresponder; y aceptar las medidas de inserción laboral, orientación y formación que (en teoría) proponga la administración autonómica.

En Andalucía en 2014 se presentaron 55400 solicitudes de esta prestación, que es tramitada a través de los servicios sociales municipales aunque es gestionada en las diputaciones provinciales. De éstas, se concedieron 33068 que eran, según la administración, las que cumplían los requisitos estipulados en el decreto que las regulan ${ }^{4}$. Llama la atención que en 2007 se presentaron 22466 solicitudes, reflejando cómo la crisis económica ha multiplicado la situación de exclusión social en esta comunidad autónoma. Según datos de la Encuesta de Población Activa en el año 2015, 1,3 millones de andaluces se encontraban en situación de desempleo, lo que constituye el 36,3\% de la población activa. Además, numerosas familias no tienen ningún miembro trabajando, lo que agrava aún más la situación de emergencia social en esta comunidad autónoma.

Dentro del marco andaluz, para esta investigación se han elegido tres municipios de más de 40000 habitantes de la provincia de Cádiz: Jerez de la Frontera, El Puerto de Santa María y San Fernando. El estudio se ha centrado en esta provincia por ser una de las más castigadas por el desempleo y la pobreza severa en el estado español según

\footnotetext{
${ }^{3}$ Existen diferentes modelos de RMI, pero todas tienen en común los siguientes puntos: a) son complementarias, y no sustitutivas, al sistema de protección social, por lo que se diferencia del subsidio universal; b) son prestaciones de carácter universal, a la cual puede acudir cualquiera que demuestre una situación de necesidad; c) tienen carácter de derecho o de cuasi-derecho; y d) intentan cubrir necesidades fundamentales mientras dure la situación de carestía (Euzeby 1989).

${ }^{4}$ Según la administración autonómica, el $68 \%$ de los usuarios estaba sin estudios, el $72.25 \%$ eran mujeres, y el $60 \%$ estaba dentro del tramo de edad de 25 a 44 años. Estos perfiles serán utilizados posteriormente en la selección de los informantes para las entrevistas.
} 
diversas fuentes (APDHA 2012; Cáritas 2012). Según datos de Cáritas, la provincia de Cádiz encabeza los índices de pobreza, exclusión social y de economía sumergida de la región andaluza y del conjunto del país (Cáritas 2012). En dicho territorio existe un gran número de habitantes cuyos ingresos se sitúan por debajo del $60 \%$ de la renta media disponible en el conjunto del estado. En municipios con más 40000 habitantes, el porcentaje de personas con bajos ingresos es mayor. En este contexto, la RMI se convierte en la última red de protección para personas que agotaron prestaciones por desempleo.

Este artículo trata de conocer las estrategias de acumulación de activos de usuarios de la política social de la RMI, e investigar qué percepciones tienen estas personas sobre su situación social y la prestación. En primer lugar este artículo repasa el marco teórico de la acumulación de activos, reflexionando sobre los conceptos de agencia y estructura en el estudio de las estrategias de los actores sociales. En segundo lugar, se describe la metodología utilizada en este estudio, basado principalmente en relatos de vida y testimonios orales de informantes-tipo (usuarios) e informantesclave (responsables políticos y técnicos implicados en esta política social). Posteriormente se narran los relatos de vida de una muestra de tres usuarios, seleccionados según su representatividad teórica en relación a los tipos de activos y estrategias desplegadas para lidiar con la pobreza. Finalmente se estudian de manera comparativa los testimonios de los tres informantes con el objeto de identificar diferentes estrategias y analizar el rol de la RMI en dichas estrategias individuales.

\section{ESTRATEGIAS INDIVIDUALES ANTE LA POBREZA: REPENSANDO LA PERSPECTI- VA DE LA ACUMULACIÓN DE ACTIVOS}

El concepto de estrategia es fundamental para comprender el comportamiento de las personas que se encuentran en situación o en riesgo de exclusión social. Hablamos de estrategia para referirnos a las prácticas sociales que, con cierto componente de intencionalidad e innovación, diseñan y llevan a cabo los actores sociales con el objeto de satisfacer sus diversas necesidades (Tobio 2005). Este artículo estudiará las estrategias individuales. El estudio, no obstante, deberá ser complementado con el análisis de estrategias familiares, basadas en la reciprocidad y distribución de recursos en el marco del grupo de convivencia, pues numerosos análisis demuestran que los grupos domésticos tienen un papel fundamental en el desarrollo de estrategias en situaciones de pobreza y precariedad (Han 2011). Aunque en este trabajo se tratará de ubicar las estrategias individuales en el contexto de los grupos domésticos de los sujetos, conocer en profundidad las estrategias familiares requiere un tipo de aproximación diferente (Lewis 1961). En un futuro se abordarán las estrategias familiares.

Para el estudio de las estrategias de usuarios de las RMI se utilizará una versión de la perspectiva teórica de la acumulación de activos propuesta por Caroline Moser (2008). Este modelo fue desarrollado inicialmente para el estudio de las políticas de reducción de la pobreza en los países del sur y posteriormente ha sido aplicado a la investigación de otros procesos sociales relacionados con la pobreza, como las migraciones internacionales. Se parte de que las diferentes estrategias de los sujetos sociales persiguen acumular activos o capitales en sus diversas formas: económico, cultural, social, etc. Un activo es una reserva de recursos naturales, humanos, sociales y financieros que 
pueden adquirirse, desarrollarse, mejorarse y transferirse a través de generaciones (Ford 2004). La pobreza y el bienestar no es únicamente una cuestión de ingresos, gastos y consumo: deben ser analizados no solo en relación a los ahorros financieros sino también en términos de inversiones sociales y humanas (Sherraden 1991; Moser, Sparr y Pickett 2007). Hablar de ingresos nos lleva a hablar de consumo, pero hablar de activos nos permite reconocer cómo piensa la gente e interacciona con el mundo. Los sujetos sociales piensan a largo plazo, persiguen objetivos a largo plazo. De este modo, los esfuerzo de los individuos por sobrevivir, prosperar o escapar de la pobreza pueden entenderse como acciones semi-conscientes destinadas a aumentar la cartera de activos individual o familiar a diferentes escalas temporales.

Los activos o capitales que los individuos y grupos familiares tratan de acumular son variados. Moser (2006), basándose en autores como Putnam (1993) o Portes (1998) y Bebbington (1999), ofrece una tipología de activos o capitales. El capital físico son las existencias de equipamientos, infraestructuras y recursos productivos propiedad de individuos, empresas o países. El capital financiero son los recursos financieros disponibles para la gente. El capital humano se refiere a las inversiones en educación, salud y nutrición. La fuerza laboral depende en buena medida de estas inversiones de capital humano, puesto que la cualificación y la salud son fundamentales para la inserción en el mercado de trabajo. El capital social es definido por Moser como el conjunto de «reglas, normas, obligaciones, reciprocidades y confianza que están incardinadas en las relaciones sociales, las estructuras sociales y los dispositivos institucionales" (Moser 2006: 6). Este capital opera tanto a nivel micro (en individuos, hogares y comunidades locales) como a nivel macro (en las normas de instituciones políticas, económicas y de la sociedad civil). Por último, el capital natural es definido como el conjunto de recursos provistos por el medio ambiente, como el petróleo, el agua, la atmósfera, los minerales, el clima, los bosques. Estos recursos son vitales tanto en enclaves rurales como en urbanos.

El concepto de acumulación de activos está relacionado con el concepto de agencia. La agencia puede definirse como la capacidad de los individuos para actuar con independencia y para elegir libremente sus propias opciones. Por el contrario, la estructura se refiere a aquellos factores que determinan, condicionan o limitan a los actores sociales y sus decisiones (Barker 2005). La agencia es la capacidad para seguir nuestra propia voluntad, independientemente de la influencia de factores estructurales que afectan a nuestra conducta. Esta habilidad depende: i) de la estructura de creencias que se ha formado a partir de nuestras experiencias; ii) de las percepciones sociales e individuales sobre las estructuras sociales y las circunstancias de nuestro entorno; y iii) de la posición con la que se nace.

A pesar de las interesantes aportaciones del enfoque de la acumulación de activos y del concepto de agencia para estudiar las estrategias individuales ante situaciones de exclusión y pobreza, es preciso señalar algunas objeciones que dan lugar a que optemos por reorientar la mirada teórica de esta investigación. En concreto, estos conceptos presentan un marcado sesgo ideológico. Hasta cierto punto, constituyen una variante moderna de la teoría del actor racional, que sobredimensiona la libertad (y, con ello, la responsabilidad) de los sujetos para actuar y decidir su destino. No obstante, como Callejo (2005) ha puesto de manifiesto, la estrategia está estrechamente ligada a la posición en la estructura social que ocupan los sujetos. Desde la 
posición social se percibe el conjunto o parte de la estructura y esta percepción condiciona las posibilidades de acción de los sujetos. Por no hablar de la influencia de variables estructurales como el género o la etnicidad en las prácticas de los actores sociales. Es preciso añadir que, siguiendo a Bourdieu (1998), la acumulación de activos o capitales es el resultado de una combinación variable de decisiones estratégicas y constricciones y determinantes estructurales. Sin tener en cuenta las desigualdades sociales (que vienen marcadas por la posesión de los diferentes tipos de capital) no es posible investigar las prácticas de los actores sociales. Con el objeto de analizar la interacción entre factores individuales y sociales, y cómo éstos afectan a los comportamientos, decisiones y procesos de distinción de los actores sociales, Bourdieu propone el concepto de habitus, que define como esquemas asociados a la posición social que influyen en el modo en que los actores sociales piensan y actúan. Afirma que estos esquemas son "estructuras estructuradas y estructurantes": estructuradas dado que son resultado de la interiorización de las estructuras sociales por parte del sujeto, y estructurantes dado que al mismo tiempo construyen, a través de las prácticas, las estructuras sociales mismas (Bourdieu 1984). El autor francés trata así de superar el viejo dilema sociológico entre objetivismo y subjetivismo.

En una línea similar, la propuesta de Archer (2003) puede contribuir a analizar las estrategias individuales. Afirma que los actores disponen de diferentes grados de libertad a la hora de determinar sus cursos de acción (Archer 2007: 6). Entiende que lo que media entre las estructuras sociales y la agencia es la reflexividad, que define como una conversación interna a través de la cual los sujetos fijan su lugar en la sociedad, sus intereses y sus planes para acciones futuras (Archer 2003). De este modo, estos conceptos nos permiten comprender las estrategias en términos de la interacción entre las cambiantes condiciones estructurales y las elecciones reflexivas de los actores sociales (Mrozowicki, Pulignano y Van Hootegem 2010). Asimismo, la distinción de De Certeau (1996) entre estrategia, que implica reflexividad, y táctica, que presenta un mayor componente de inconsciencia, puede contribuir a discernir en modo en que agencia y estructura intervienen en los comportamientos de los sujetos sociales.

La perspectiva que proponemos en este artículo sostiene que las estrategias individuales de acumulación de activos por parte de usuarios de las RMI no se desarrollan en un vacío socio-cultural, sino que se basan en recursos culturales que incluyen creencias prácticas y morales (normas, costumbres, reciprocidades) que son influenciadas por las experiencias individuales y colectivas de las estructuras sociales (estrechamente relacionadas con factores como la posición de clase, el género o la etnicidad).

\section{METODOLOGÍA: LA HISTORIA DE VIDA COMO HERRAMIENTA DE INVESTIGA- CIÓN EN POLÍTICA SOCIAL}

Con frecuencia, las investigaciones cualitativas sobre los procesos de exclusión se han inspirado en el enfoque de la "cultura de la pobreza" formulado inicialmente por Oscar Lewis (1972). Según este modelo los pobres son representados como personas presas por los condicionamientos de la "cultura", entendida como una realidad externa que posee sus propias dinámicas de transmisión y autoperpetuación. Otros dis- 
cursos sociales, en cambio, enfatizan la agencia de los individuos y responsabilizan a los pobres de su destino social (Wacquant 2001). Nuestra aproximación trata de huir de ambos extremos — determinista y subjetivista - prestando atención a las causas estructurales de la pobreza, pero también al modo en que los sujetos sociales perciben su situación, reflexionan sobre las instituciones y dinámicas sociales, y desarrollan planes de acción (Hogget 2001).

Para conocer las estrategias de acumulación de activos de los actores sociales no es suficiente estudiar cifras y estadísticas, sino que es preciso contar la vida de los individuos y las familias. Es necesario, por tanto, "comprender las relaciones sociales dentro de familias, hogares y comunidades, y a la vez sus relaciones estructurales con actores externos" (Moser 2008: XV). El análisis de las situaciones de pobreza y exclusión social demanda combinar mediciones económicas y narrativas cualitativas.

Esta investigación se interesa por los relatos de vida de usuarios de las RMI. Las narraciones de los sujetos sobre su vida, solicitadas por los investigadores, nos permiten adentrarnos en el modo en que agencia y estructura se conectan (Lewis 2008), mostrando cómo los individuos leen los hechos sociales y producen sus propias expectativas, visiones y estrategias (Roca y Florido 2015). Las narrativas personales pueden ser entendidas como formas de respuesta y resistencia de los actores sociales a los discursos hegemónicos sobre la pobreza (Pemberton et al. 2016). La historia de vida, además, permite humanizar (Plummer 1983) una investigación sociológica en la que ha predominado enfoques fríos y despersonalizados.

La investigación se basa en un total de 46 entrevistas semiestructuradas a informantes-tipo $(n=40)$ —usuarios de la RMI- y a informantes-clave $(n=6)$ - trabajadores sociales de los Ayuntamientos de Jerez, El Puerto de Santa María y San Fernando, trabajadora social de la Diputación de Cádiz, la técnico responsable del salario social de la Diputación de Cádiz y un responsable político del gobierno andaluz que forma parte de la comisión que aprueba la concesión de esta política social一. Los usuarios entrevistados eran en su mayoría mujeres $(n=27)$, frente a 13 varones, de diferentes franjas de edad: entre 16 y 35 años $(n=12)$, entre 36 y 55 años $(n=26)$ y entre 55 y 64 años $(n=2)$. Respecto al estado civil, los informantes se encontraban en su mayoría casados $(n=18)$, aunque también separados o divorciados $(n=13)$ y $\operatorname{solteros}(n=9)$. En relación a los estudios la mayoría no tenía estudios $(n=24)$, y sólo algunos tenían formación primaria $(n=8)$, secundaria $(n=5)$ o universitaria $(n=3)$. Respecto al número de hijos a su cargo, los entrevistados presentaban diferentes situaciones: sin hijos $(n=9)$, un hijo $(n=16)$, dos hijos $(n=12)$, o tres o más hijos $(n=3)$.

Las entrevistas a informantes-tipo se realizaron en 2014 y 2015 en los despachos de las Áreas de Bienestar Social de los ayuntamientos de los municipios de la muestra, cedidos desinteresadamente por los trabajadores sociales. A pesar de la significación social que dicho espacio tiene para los usuarios de la RMI, pues es el lugar en el que son sometidos a examen y vigilancia gubernamental ${ }^{5}$, consideramos que el rapport alcanzado durante las conversaciones y la garantía de confidencialidad ayudaron a superar dicho obstáculo. En el transcurso de las entrevistas, algunos benefi-

\footnotetext{
${ }^{5}$ Ayala y García (2009), por ejemplo, ilustran cómo los perceptores de la RMI de origen gitano en la Comunidad de Madrid presentan altos niveles de desconfianza en sus interacciones con los Servicios Sociales.
} 
ciarios de la RMI hicieron referencia a actividades ilegales y a realidades que, de haber sido conocidas por los administradores del subsidio, podrían haber implicado la pérdida del derecho. Esta realidad refleja que se produjo una relación de confianza, y el contenido de los relatos puede considerarse, a grandes rasgos, un indicador de las estrategias y prácticas de los sujetos. Por otro lado, las entrevistas a informantesclave se llevaron a cabo en sus lugares habituales de trabajo. El guión de las entrevistas a los usuarios giró en torno a cinco ejes: perfil socio-demográfico, trayectoria vital (incluyendo aspectos de la vida familiar), experiencia laboral, experiencia tras recepción de la ayuda y percepciones.

\section{RELATOS DE VIDA DE TRES PERCEPTORES DEL SALARIO SOCIAL}

Del total de 40 entrevistas realizadas a los perceptores de la RMI, se han seleccionado los relatos de vida de tres de ellos. Los tres casos han sido seleccionados: por un lado, porque implican entre los tres a la totalidad de tipos de activos movilizados y acumulados por los sujetos; por otro lado, porque son los tipos de estrategias más frecuentes encontradas durante el trabajo de campo (centradas principalmente en la formación, el matrimonio y la percepción de ayudas públicas y privadas, respectivamente). Los testimonios permitirán analizar cómo los individuos que viven en la pobreza perciben su situación y construyen estrategias para sobrevivir, mejorar y, en ocasiones, ofrecer oportunidades a sus hijos. Se estudiarán, además, sus percepciones sobre la política de las RMI.

\subsection{ERNESTO: FORMACIÓN, DIVERSIFICACIÓN Y AUTO-EMPLEO}

Ernesto nació en El Puerto de Santa María (Cádiz) hace 42 años. Hijo de un oficial de la construcción y un ama de casa sin estudios, logró estudiar un módulo de formación profesional de informática compaginándolo con trabajos de verano con su padre. Cuando se tituló estuvo trabajando en otros puntos de España, pero al tener su pareja y sus padres lejos no se encontraba bien sentimentalmente. Con el tiempo utilizó la experiencia adquirida para encontrar un empleo cerca de casa, en la planta de Visteón —una filial de la automovilística Ford- donde su único hermano ya estaba trabajando como operario. Afirma que logró entrar por ser una persona polivalente y que es de sus mejores trabajos ya que estaba contratado a jornada completa, tenía buen sueldo y le permitió comprar una vivienda:

En Visteon, lo que era aquí la Ford, estuve cuatro años. Yo creo que es de lo mejores trabajos que he tenido porque era un trabajo de 40 horas. Ahí ya trabajaba mi hermano y me informó que iban a salir plazas en la empresa y logré entrar debido que, aunque soy informático, he sido y soy capaz de meterle mano a cualquier cosa. Mira que yo estuve siempre en turno de noche, que era sacrificado, pero yo lo llevaba bien porque el sueldo era bueno. Gracias a eso me pude comprar la casa, porque si no, no me hubiesen dado la hipoteca en mi vida.

A partir de 2008 despidieron a los eventuales y solo logró trabajar algunas temporadas en la empresa hasta que cerró en 2011. En ese momento comenzaron las difi- 
cultades económicas y la ayuda de la familia se volvió fundamental para sufragar los iniciales problemas de impago que se le avecinaban por la situación de desempleo. Los padres de su pareja, con la que convive sin estar casado y sin hijos, son los que les ayudan económicamente. Su pareja, además, trabaja esporádicamente de dependienta en un comercio, pero los ingresos de dicho trabajo no superan los 100 euros mensuales. Afirma que su situación económica es la que les ha hecho decidir no tener hijos.

Tener que pedir ayuda constantemente a la familia le hizo sentirse frustrado, por lo que buscó empleo en cualquier sector. Encontró trabajo en una empresa de placas fotovoltaicas en un municipio vecino. Aunque le hicieron contrato indefinido esta empresa también cerró después de un año y medio debido a la retirada de las ayudas estatales para energías renovables. Desde entonces ha optado por la diversificación, buscando empleo en cualquier sector y actividad. Sin embargo, sólo ha encontrado trabajos muy precarios, de corta duración, y ha tenido que depender de ayudas sociales.

La falta de empleo debilita su autoestima. Se replantea además su estrategia de búsqueda de empleo, que consiste básicamente en explicar verbalmente su disposición a aceptar cualquier trabajo y a destacar sus habilidades y experiencias en función de las características de la empresa. No obstante, explica, lo más duro es la sensación al volver a casa con las manos vacías:

Nunca me ha faltado el trabajo, pero ha llegado el momento que ni buscando trabajo, (...). Lo que intento cuando lo entrego es decir: "Mira, que lo que haga falta". Porque yo no solamente entrego el curriculum, lo entrego y lo explico. Intento explicarlo según el sitio. (...) pero es que hoy en día ni eso te encuentras en una situación que..., muy de impotencia. Lo duro del tema este es que cuando yo llego a casa siempre me preguntan: "bueno, ¿has encontrado trabajo o algo?", y te sientes mal porque dices: "Joder!, si yo me pateo polígonos y me pateo cada día".

Además de la búsqueda de empleo, Ernesto contempla la posibilidad del autoempleo personalizando camisetas.
Ahora mismo me he apuntado a unos cursos para nuevos emprendedores, porque tengo una idea de montar mi propia empresa. Pero claro, falta lo que falta: la parte económica. Precisamente hoy empieza en el curso el tema financiero (...). A ver si nos dan alguna pista de cómo conseguir dinero o que algún banco te haga caso, que es difícil, porque en mi situación lo tengo bastante complicado. Llevo tiempo pensando en el tema y tal, el tema de emprender. Y alguna cosita que hago relacionado. No lo estoy haciendo en plan profesional, porque es que no puedo por falta de recursos, pero alguna cosa sí, porque lo que hago es, tunear no, sería personalizar camisetas, y mi intención es hacerlo más.

La percepción del salario social se ha combinado con la ayuda económica de familiares para hacer frente a los gastos de hipoteca, asegurando su supervivencia y evitando ser desahuciados (circunstancia al borde de la cual afirma haberse visto en dos ocasiones). Percibe el salario social como un alivio para la familia, pues no tienen que ayudarles económicamente durante el disfrute de la prestación. Al no tener ahorros, señala, tiene miedo de perder su vivienda:

Y ahora mismo estamos tirando gracias a Dios porque tenemos familia cerca, si no tuviéramos familia, nada de nada, porque realmente nos están echando un cable muy gordo. 
$\mathrm{Y}$ ahora nos ha venido el salario, pues tenemos seis meses para por lo menos no atosigar a la familia. Nosotros no atosigamos, pero así se sentirán también un poco más aliviados la familia porque son los que nos están ayudando. Porque no tenemos nada de ahorro, nada de nada, y nos hemos visto ya un par de veces a las puertas de empezar a devolver letras y estar en situación de impago y el miedo a que te quiten la casa.

Para Ernesto es muy dura la experiencia de movilidad social descendente. Afirma que el salario social es "un parche", y que el desempleo y depender de ayudas sociales le hizo sentirse mal, especialmente al principio:

Yo esta casa [servicios sociales] no la he pisado nunca. Con la crisis me he visto obligado a llegar hasta aquí. Al principio pues te choca y te sientes mal y tal, porque esto es una cosa muy delicada. Yo era un tío que trabajaba, que no lo ganaba mal y tal. Igual que a mi mujer, bueno mi pareja porque no estamos casados, pero nos está yendo a los dos como el culo.

Señala que pensaba que antes los servicios sociales estaban para casos extremos y que hoy son muchos los pobres como él. Afirma que se considera "pobre" y antes de la crisis y de perder el trabajo se sentía de "clase media". Considera que esta experiencia ha sido una "cura de humildad" ya que él no esperaba llegar a padecer esta situación: "Pensaba que esto a mí jamás me pasaría y mira, ¡toma castaña!».

\subsection{El RELATO DE LOLI: ESTRATEGIA MATRIMONIAL Y MOVILIDAD INTERGENERACIONAL}

Loli nació en Jerez de la Frontera hace 33 años en el seno de una familia desestructurada a consecuencia de las drogas. Cuando sólo tenía 11 años su padre falleció. Su madre murió cuando tenía 18 años por motivos relacionados con las drogas. Desde pequeña ha estado cuidada por su abuela materna y no fue al colegio. Actualmente no sabe leer ni escribir. A los 16 años se emparejó con un chico mayor que ella que traficaba con drogas, reeditando en cierta medida la vida que desarrollaron sus padres. Narra que aunque la relación nunca le fue bien, tuvo dos hijas. La actividad ilegal de su esposo les permitía vivir cómodamente. La entrada en prisión de su marido supuso un problema económico para la familia, aunque para ella fue una oportunidad para desvincularse del mundo de la droga, de su pareja y vivir más tranquila. Se separó del marido y comenzó una relación con otro hombre. Actualmente vive en la vivienda heredada de su madre con sus dos hijas de 10 y 15 años. Su pareja vive con sus padres en un pueblo de la Sierra de Cádiz, y los fines de semana los tres van al pueblo para estar juntos.

Afirma sentirse "feliz" y haberse "quitado un peso de encima" a pesar de ser pobre; aunque reconoce que sus hijas no se han adaptado a la nueva situación económica:

Yo soy ahora soy feliz. Me he quitado el peso de encima. Ahora tengo tranquilidad. A lo mejor para mis hijas es un trauma, porque a la mayor la estoy llevando a un psicólogo. La mayor tiene una obsesión que dice que no quiere ser pobre, como yo digo. Valora más el dinero porque ella ha vivido ese momento bueno que pasamos económicamente. Yo ahora mismo, pa mí, estoy en la mejor etapa de mi vida. Estoy tranquila. Estoy que he cogido 18 kilos. Antes era un sin vivir porque vivía de la droga y yo no quería esa vida para mí. 
La estrategia de Loli tiene dos componentes. Primero, a corto plazo, espera que su pareja reciba una herencia y con esa cantidad montar un negocio de elaboración de queso. Afirma que su novio es el "príncipe" que ella busca y que ella lo "cogió":

Mi idea es que mi novio coja la herencia. Como ellos tienen un campo que lo van a partir, pues la madre le va a dar su parte antes y vamos a tener cabrillas y hacer quesos y demás. Esa es mi idea. Y yo he encontrado el príncipe que yo buscaba. Él es más chico que yo. Tiene 26 años y soy su primera novia. Es un campurro que lo he cogido yo y desde que lo que vi dije: "Este es pa mi».

Narra que tenía antecedentes penales de cuando vivía con su ex marido y que la policía le paraba con frecuencia. Temía que este estigma enturbiara las relaciones con la familia de su nueva pareja en el campo. Una familia, afirma, en la que impera el amor, el respeto y la honradez, a diferencia del entorno en el que ella se crió:

Otra vida totalmente diferente porque ellos son del campo, trabajadores. Y todos allí se quieren y se respetan y honrá. Quillo, una vida tranquila. Así es que mi situación ha cambiao y estoy bien.

A medio plazo, su estrategia de acumulación de activos se centra en invertir en la educación de sus hijas, para que tengan estudios universitarios y puedan ascender socialmente.

Mis expectativas de futuro es que mi hija termine el instituto, porque yo le he dicho que cuando terminé se vaya pa la carrera. Ella quiere estudiar medicina. Tú ves a la niña y parece que la niña no es mía. Es tó finolis. Sabe un montón. Me dice de tó y yo, "¡Ojú, chiquilla! ¡Cómo sabes!». Será porque como yo nunca he estudiao le he puesto mucho hincapié en que ellas lo hicieran.

Loli relata que esta es la primera vez que acude a los Servicios Sociales ya que siente vergüenza y, aunque en ocasiones lo ha necesitado, este sentimiento le ha frenado. Recibe alimentos de Cáritas a través de una amiga usuaria de esa ONG para no tener que ir personalmente. Cuenta, no obstante, con ayuda económica de su actual pareja:

Esta es la primera vez que vengo a los Servicios Sociales, porque a mí me da mucha vergüenza. Incluso necesito a veces comida pero no voy. No me veo todavía como para ir a Cáritas. Es mi amiga la que me da cosas de Cáritas porque le dan una barbaridad (...), no voy a asociaciones y ni quiero ir porque me da vergüenza. El chavalito este me ayuda en lo que puede a mí y a las niñas, a las niñas le va comprando ropa si les hace falta.

En relación al salario social, Loli critica la escasa cuantía, la tardanza y el exceso de trámites burocráticos que es preciso sortear para solicitarla. Señala que no tiene sentido que tarde varios meses en recibirse, dada la urgencia de las necesidades. Señala que no vale para mucho y no sirve para salir de la pobreza: "Es una medida necesaria pero no vale pa mucho porque el dinero no te saca de la pobreza". Afirma que preferiría un puesto de trabajo con el que aprender para poder valerse por sí misma. Su experiencia en entrevistas de trabajo ha sido dura, al no ser capaz de expresarse verbalmente con soltura. Demanda, por tanto, formación para el empleo: "Yo lo he pasado muy mal, a mí me han llamado para entrevistas y me las veía y me las deseaba porque yo no sé explicarme. No es tan fácil. A mí lo que me gustaría es que me dieran cursos para que me formaran". 


\subsection{LUISA: UNA HISTORIA DE CUIDADOS}

Luisa nació hace 55 años en un pequeño pueblo de la provincia de Córdoba, en el seno de una familia estructurada pero con pocos recursos. Su madre, sin estudios, dedicada toda su vida a las labores del campo y su padre fue trabajador del mar y posteriormente vendedor de helados en un quiosco cerca de la playa de El Puerto de Santa María.

Su madre perdió la visión y comenzó a sufrir ataques epilépticos y tuvo que hacerse cargo de sus cuatro hermanos menores (dos varones y dos mujeres), por lo que no pudo ir a la escuela. Al poco tiempo su padre falleció. Luisa piensa que este hecho le ha limitado toda su vida, impidiéndole desenvolverse con éxito en el mercado de trabajo. Sus hermanos y hermanas, en cambio, aunque no tienen estudios, sí lograron un desarrollo profesional y se casaron. Considera que el bajo capital cultural de sus padres es la principal causa de que ella haya tenido un capital cultural bajo:

Yo valoro la educación que me han dado mis padres como negativa, porque si no me hubiesen quitado de estudiar yo hubiese tenido más estudios y hubiese estado hoy mejor, y yo no tengo más estudios en primer lugar porque mis padres no tenían estudios.

A pesar de todo, ha trabajado muchos años de limpiadora y portera en centros escolares, además de como dependienta en el quiosco familiar. Las adversidades han hecho que esté muy unida a sus hermanos, que viven todos en el mismo barrio. Se ayudan mutuamente. Loli está soltera y tiene una discapacidad reconocida del 66 por ciento por artrosis y obesidad. Recibe una pensión no contributiva de 366 euros mensuales, con la que vive y ayuda en ocasiones a su familia.

Manifiesta que haber centrado su vida en cuidar a familiares ha provocado además que no haya podido establecer vínculos sociales con otras personas, quedando soltera y sin descendencia. Se siente sola y con "Complejos" respecto a su físico:

Yo achaco mi soltería no sólo a la dedicación a mi familia, sino que también he pasado
mucho con mis padres, ellos me han enseñado un mundo que aunque se llevaban bien,
no sé cómo explicarte, no vi felicidad. Sola es verdad que se pasa mal, pero yo ahora
mismito no estoy mal. Solo estoy mal cuando echo las llaves de la puerta por la noche,
porque por el día hago de todo estoy para arriba y para abajo, pero cuando llega la no-
che ahí nos vemos Pepa (...). Me llamaron de Juan y Medio [un programa de televisión
autonómica en el que emparejan a personas mayores] (...) y dije no porque me da mu-
cha vergüenza (...). Yo reconozco que tengo más complejo que soledad. Mi complejo me
puede para todo incluso para salir con la agrupación, tener que ponerme un disfraz y
ver que a aquella le queda como un figurín y a mí como una mesa estufa, es que no
puedo.

Debido a su estado de salud se siente incapaz de realizar trabajos físicos y, al no tener estudios, no puede aspirar a otro tipo de empleos. "No sé en qué puedo trabajar por eso no busco empleo. Con las manos no puedo trabajar, a consecuencia de la espalda no me puedo ni agachar y no puedo coger peso. Dime tú qué puedo hacer". Como ya recibe una prestación, el salario social que le corresponde es sólo de 35 euros mensuales, que se suman a los 366 que ya recibía. Ha solicitado la prestación en cuatro ocasiones y siempre se ha resuelto favorablemente. No busca empleo y no encuentra ninguna salida a su situación de dependencia de las ayudas sociales. 
En ocasiones también solicita ayuda de alimentos en la Cruz Roja, aunque reconoce no ir por vergüenza a Cáritas y no le compensa ya que dada su obesidad no consume los alimentos que allí se distribuyen:

He ido a la Cruz Roja pero en los dos años que estoy apuntada solo me han llamado dos veces. A Cáritas me da vergüenza ir. Verás, las cosas que da Cáritas yo no las utilizo porque siempre estoy a dieta, entonces garbanzos, habichuelas, galletas... Todo eso no lo como. Entonces, a lo mejor a mi hermano Francisco, como estamos en la Iglesia San Marcos, lo han llamado para descargar los camiones y le han dado comida y él me ha dado a mí. Pero es que no utilizo casi ná, y yo digo pasar la vergüenza para coger una bolsa para después regalarla, si dieran verduras en vez de esa comida. Porque para pasar la vergüenza yo, que la pase quien utilice esa comida.

La estrategia económica de Luisa es una estrategia principalmente de supervivencia, basada en la recepción de ayudas sociales de administraciones y entidades del tercer sector.

Luisa considera que el salario social es una "puerta encajadita", una medida que ofrece una salida provisional a las personas que como ella, están en la "pobreza absoluta". No obstante, critica la tardanza en la recepción de la prestación y el poco tiempo que es posible disfrutarlo (6 meses), que no permite que los perceptores superen la situación en la que se encuentran:

El salario tarda mucho, es urgente y tardan. Aunque cierto es que el salario es un dinero que no es tuyo y te dejan una puerta encajadita, aunque ya que echas tantos papeles para el salario, y si ven que estamos en la absoluta pobreza, te dan poco dinero y durante poco tiempo, porque cuando nos lo quitan de nuevo estamos en la pobreza. Yo pienso que aunque hubiera que dar menos cantidad de salario, este dinero debía alargarse por más tiempo ya que seis meses son muy pocos. Y no digo solo por el caso mío, sino porque hay personas que no tienen tiempo en levantar cabeza, no les da tiempo a buscar nada.

\section{ANÁLISIS}

La comparación de las narraciones biográficas y las percepciones de Ernesto, Lola y Luisa nos permiten investigar diferentes tipos de estrategias de acumulación de activos.

Ernesto, a pesar del bajo capital cultural de sus padres consiguió una titulación de formación profesional. Aunque la mayor parte de su carrera no ha trabajado de informático, las habilidades y conocimientos adquiridos a lo largo de su trayectoria formativa y laboral le permitieron conseguir empleo estable y bien remunerado en su municipio, y adquirir una vivienda a través de un préstamo hipotecario. La deslocalización o cierre de las empresas en las que había trabajado a partir de la crisis de 2008 le empujan a una movilidad social descendente. En el momento de la entrevista se encontraba al borde de la exclusión, evitando el impago de la hipoteca y sobreviviendo gracias a la percepción de la RMI, la ayuda económica familiar y la diversificación en la búsqueda de empleo (que le ha permitido conseguir alguna ocupación temporal y mal remunerada).

Loli ha vivido siempre en una situación de exclusión social. Sus padres fallecieron siendo ella joven a causa de las drogas y fue criada por su abuela. No tuvo oportunidad de ir a la escuela. La actividad delictiva de su primer marido, con quien tuvo 
dos hijas, le permitió vivir desahogadamente a pesar de no estar satisfecha con la relación sentimental. La entrada en prisión de su entonces esposo la empujó a acudir a los servicios sociales en busca de ayuda económica. El activo más importante de Loli es su actual pareja. A quien afirma que "ha cogido". El pequeño patrimonio familiar y la ayuda económica de su pareja, junto a la RMI, le permiten sobrevivir. Afirma dedicar un enorme esfuerzo en la educación de sus hijas, de las que espera que realicen estudios. Su sueño es crear su propio negocio de elaboración de quesos con la herencia familiar de su actual pareja.

Luisa también ha padecido la pobreza desde pequeña. No pudo ir a la escuela porque tuvo que hacerse cargo de su madre enferma y sus cuatro hermanos menores. Trabajó muchos años de limpiadora o portera en centros escolares y como dependienta en el quiosco familiar, sin embargo, el desarrollo de la artritis y otras enfermedades le hicieron imposible seguir realizando trabajos manuales. Tiene reconocido un $66 \%$ de discapacidad y recibe una pensión no contributiva muy reducida que compagina con la RMI. En ocasiones compagina estas ayudas con ayuda alimenticia de la ONG Cruz Roja, y las relaciones de ayuda con sus hermanos, que viven en el mismo barrio, son fundamentales para vivir el día a día. Luisa se siente sola y no tiene expectativa de salir de la pobreza.

La primera diferencia entre los casos presentados es el capital cultural disponible, que refleja diferentes procedencias de clase entre los sujetos estudiados. Los estudios de formación profesional de Ernesto le dieron una serie de conocimientos y competencias que le ayudaron a vivir bien hasta el inicio de la crisis económica. Loli y Luisa, en cambio, no asistieron a la escuela y no saben leer ni escribir. Por el encarcelamiento de su marido, en el caso de Loli, y por motivos de salud, en el caso de Luisa, ellas ya estaban en una situación de pobreza cuando la crisis económica irrumpió en España. Se confirman, de este modo, conclusiones de investigaciones previas sobre la influencia de la posición social de los beneficiarios de la RMI y sus discursos en torno a la prestación (Ayala 2013).

Una segunda diferencia de las estrategias de las personas de la muestra son sus perspectivas: mientras Ernesto busca activamente empleo e incluso apuesta por el autoempleo, Luisa ha perdido toda expectativa de encontrar un puesto de trabajo de acuerdo a sus limitaciones. Loli, en cambio, deposita su confianza en los estudios de sus hijas, expresando un sueño de movilidad social intergeneracional. En el día a día, la elección de pareja ha sido la forma en que se ha asegurado su supervivencia y, en un futuro, espera que le permita montar un pequeño negocio.

La existencia de diferentes estrategias en los tres sujetos reflejan diferentes niveles de agencia (reflexividad). Pero esta agencia no puede separarse de las condiciones estructurales de los sujetos. Los capitales con los que parte Ernesto, que ha experimentado movilidad social descendente con la crisis económica, y los activos de Loli y Luisa, que han vivido siempre en situación de pobreza, son muy diferentes. Esto explica que el planteamiento del primero tenga un mayor componente estratégico (al menos siguiendo la racionalidad de orientadores profesionales e instituciones públicas), y el comportamiento de las segundas presente un componente más táctico (más reactivo a condiciones estructurales de privación). Los activos disponibles marcan diferentes niveles de libertad y reflexividad, y, en consecuencia, distintos tipos de estrategias de acumulación. 
Un elemento común en los tres relatos es la importancia de los cuidados y la ayuda familiar como un activo para asegurar la supervivencia y el bienestar. Esto coincide con estudios recientes que destacan la moral familiar respecto al amor, el afecto y los cuidados en familias en situación de exclusión en otros contextos, y que contrasta con las teorías que enfatizan los déficits culturales y de comportamiento de las personas en situación de pobreza (Daly y Kelly 2015).

Una importante coincidencia en los tres relatos es su identificación en la categoría de "pobres". Ernesto denuncia que él y muchos otros fueron engañados al identificarse como "clase media". La crisis económica lo desenmascaró: "éramos clase media, pero en realidad éramos pobres". En los relatos de Loli y Luisa también se definen a sí mismas como "pobres", aunque no afirman en ningún momento haberse sentido de "clase media".

Otro elemento común a los tres relatos es la vergüenza. El hecho de ir a los Servicios Sociales o a ONG que reparten alimentos es vivido por estas personas como una vergüenza. En una sociedad con valores meritocráticos y materialistas la pobreza se convierte en un estigma que genera dolor y sufrimiento. Loïc Wacquant (2000), por ejemplo, explica cómo el discurso hegemónico neoliberal culpabiliza al pobre de su situación social, categorizando, en ocasiones, a las explicaciones sociológicas como "excusas" que exculpan e infantilizan a los pobres por sus comportamientos desviados. El sentimiento de vergüenza es más elevado cuando se experimenta una movilidad social descendente, como en el caso de Ernesto, aunque la sensación, afirma, se va reduciendo conforme pasa el tiempo y va normalizando la situación en la que vive.

El hecho de que Ernesto haya pasado de una situación de autonomía económica a una de dependencia, y que Luisa y Loli hayan vivido siempre en situación de dependencia, refleja cómo el género interviene decisivamente en el modo en que las personas experimentan y perciben las situaciones de pobreza. Como Butler (2009) ha puesto de manifiesto, precariedad (entendida como la percepción de que nuestra vida está siempre en manos de otra persona), vulnerabilidad y dependencia, son tres elementos indisociables. La desigualdad de poder entre géneros y la construcción normativa sobre el género en nuestra sociedad ubica a las mujeres en posiciones de dependencia, vulnerabilidad y precariedad. En el caso de las informantes existe una fuerte intersección entre la clase y el género que refuerza su situación de subalternidad (Viveros Vigoya 2016). Por ello, las emociones de vergüenza son experimentadas con diferente intensidad en beneficiarios varones y mujeres. A esto es preciso añadir que más del $72 \%$ de los perceptores del subsidio sean mujeres. Este dato refleja dos cuestiones: primero, que la pobreza afecta en mayor proporción a las mujeres; segundo, que en situaciones de pobreza, las mujeres adquieren un papel central en la interacción con las administraciones encargadas de la protección social. Estas dos realidades se corresponden con dos dimensiones del concepto de feminización de la pobreza, y refuerzan la tesis de que las crisis económicas suponen una intensificación del trabajo de las mujeres (Gálvez y Rodríguez 2011).

Por último - y posiblemente relacionado con lo anterior-, es preciso señalar que el discurso de los entrevistados sobre su situación y experiencia es un relato totalmente despolitizado. Ninguna de las personas entrevistadas hizo referencia a culpables externos de su situación (a excepción de las malas decisiones de sus padres). Cuando Ernesto hablaba de su situación, hacía referente al concepto abstracto de la 
"Crisis". Ninguno de los informantes hizo referencia a la gestión política de la crisis, a decisiones políticas o al papel de ninguna institución social en la generación de la pobreza.

El salario social es percibido por los usuarios como un "parche", una "puerta entreabierta", es decir, una política social de mínimos y muy defectuosa que permite temporalmente escapar de las vicisitudes más extremas de la pobreza, pero que, al no estar acompañada de otras políticas sociales, es manifiestamente insuficiente para superar la situación de necesidad en la que se encuentran. Este subsidio y su sistema de administración operan como lo que Ferguson (1990) denominó en el contexto del desarrollo internacional "máquina anti-política", que despolitiza las realidades sobre las que interviene. De este modo, la RMI, tal y como está diseñada y es gestionada por los Servicios Sociales, es una política social plenamente coherente con la lógica neoliberal que responsabiliza a los individuos de su destino (Wacquant 2000) y representa la pobreza, la precariedad, la vulnerabilidad y la dependencia, desresponsabilizando al Estado y a otras instituciones sociales que tradicionalmente han desempeñado un papel redistribuidor y regulador.

\section{CONCLUSIONES}

En este artículo se ha aplicado el enfoque de la acumulación de activos al estudio de las estrategias individuales de beneficiarios de la RMI en Andalucía. El punto de partida es que las estrategias de los sujetos persiguen acumular y/o movilizar diferentes tipos de activos o capitales (Moser 2008). Hablar de estrategia implica reconocer cierta racionalidad, intencionalidad, reflexividad y libertad a los sujetos sociales, esto es, subrayar la agencia. El enfoque de este trabajo, no obstante, enfatiza que las estrategias no se desarrollan en un vacío sociocultural, sino que se forman también bajo condicionamientos estructurales (normas, instituciones, economía política, relaciones de poder). Las estrategias ante la pobreza son, al fin y al cabo, resultado de relaciones dialécticas entre la agencia y la estructura.

Para analizar las estrategias individuales de beneficiarios de la RMI, se han utilizado los relatos de vida de tres usuarios del subsidio: Ernesto, Loli y Luisa. Estas narraciones han sido seleccionadas porque movilizan en su conjunto la práctica totalidad de los activos encontrados en la muestra total de personas entrevistadas y porque ilustran las tres estrategias más comunes: la formación, la dependencia de subsidios públicos y la estrategia matrimonial/familiar.

El análisis de los relatos ofrece claves para comprender las estrategias de los sujetos. Primero, el capital cultural disponible por los sujetos ocupa un lugar central en el diseño de estrategias ante la pobreza. Segundo, la posición social de origen (o la extracción de clase) de los sujetos también condiciona sus estrategias individuales y representaciones. Apoyándose en la distinción entre táctica y estrategia de De Certeau (1996), el artículo identifica diferentes niveles de articulación entre agencia y estructura en los sujetos estudiados, que se traducen en diferentes elecciones vitales y prácticas sociales. Tercero, los sujetos entrevistados destacaban la importancia de la ayuda familiar para hacer frente a las situaciones de pobreza, precariedad y vulnerabilidad. En este sentido, se refuerzan las tesis feministas sobre la intensificación del trabajo 
de las mujeres en contextos de crisis y los estudios sobre el papel amortiguador de la familia ante situaciones de pobreza. Cuarto, las narraciones desvelan la utilización de la noción de "pobre" como categoría de autoidentificación en todos los casos. Quinto, los sujetos comparten emociones de vergüenza por la situación de dependencia (familiar y respecto a instituciones públicas y privadas). Este sentimiento, no obstante, aparece desigualmente en los informantes en función del género y el origen de clase: varones y personas que han descendido recientemente en la escala social lo experimentan con mayor intensidad. Finalmente, los relatos de los perceptores son discursos altamente despolitizados, que entroncan coherentemente con la doxa neoliberal que inspira a buena parte de la política social actual.

\section{BIBLIOGRAFÍA CITADA}

APHDA. 2012. Exclusión y desarrollo social en España. Análisis y perspectivas 2012. Cádiz: Asociación Pro Derechos Humanos Andalucía.

Archer, Margaret. 2003. Structure, Agency and the Internal Conversation. Cambridge: Cambridge University Press.

Archer, Margaret. 2007. Making our Way through the World: Human Reflexivity and Social Mobility. Cambridge: Cambridge University Press.

Ayala Rubio, Ariadna y Sergio García García. 2009. "Gestión de cuerpos y actuación de resistencias en una política social. La aplicación de la Renta Mínima de Inserción de la Comunidad de Madrid". Revista de Antropología Experimental 9(2): 17-36.

Ayala Rubio, Ariadna. 2013. "De la "paga" a un derecho social: experiencias y puntos de vista de los beneficiarios gitanos sobre la Renta Mínima de Inserción". Revista de Antropología Social 22: 103-136.

Barker, Chris. 2005. Cultural Studies: Theory and Practice. Londres: Sage

Bebbington, Anthony. 1999. "Capitals and Capabilities: a Framework for Analyzing Peasant Viability, Rural Livelihoods and Poverty". World Development 27(12): 2021-2044.

Bourdieu, Pierre. 1984. La distinción. Criterios y bases sociales del gusto. Madrid: Taurus.

Bourdieu, Pierre. 1998. Practical Reason: On the Theory of Action. Palo Alto: Stanford University Press.

Butler, Judith. 2009. "Performativity, precarity and sexual politics". AIBR, Revista de Antropología Iberoamericana 4(3): i-xiii.

Callejo, Javier. 2005. "Estrategias temporales: relaciones entre tiempo de trabajo remunerado y tiempo de trabajo doméstico". Cuadernos de Relaciones Laborales 23(1): 175-204.

Cáritas. 2012. Actas del simposio: políticas sociales contra la exclusión social. Madrid: Cáritas.

Daly, Mary y Grace Kelly. 2015. Families and Poverty: Everyday Life on a Low Income. Bristol: Policy Press.

De Certeau, Michael. 1996. La invención de lo cotidiano. I. Artes de hacer. México: Universidad Iberoamericana.

Euzeby, Chantal. 1989. "El ingreso mínimo garantizado: experiencias europeas", en Cáritas (org.), Jornadas sobre prestaciones no contributivas y lucha contra la pobreza: Instituto Sindical de estudios: 51-65. Barcelona: Cáritas.

Ferguson, James. 1990. The Anti-politics Machine. "Development", depolitization and bureaucratic power in Lesotho. Cambridge: Cambridge University Press.

Ford Foundation. 2004. Building Assets to Reduce Poverty and Injustice. Nueva York: Ford Foundation.

Gálvez Muñoz, Lina y Paula Rodríguez Maroño. 2011. "La desigualdad de género en las crisis económicas". Investigaciones Feministas 2: 113-132.

Han, Clara. 2011. "Symptoms of Another Life: Time, Possibility, and Domestic Relations in Chile's Credit Economy". Cultural Anthropology 26(1): 7-32.

Hogget, Paul 2001. "Agency, Rationality and Social Policy". Journal of Social Policy 30(1): 37-56. 
Lewis, David. 2008. «Using Life-Work Histories in Social Policy Research: The Case of Third Sector/ Public Sector Boundary Crossing". Journal of Social Policy, 37(4): 559-578.

Lewis, Oscar. 1961. Antropología de la pobreza. Cinco familias. México: Fondo de Cultura Económica.

Lewis, Oscar. 1972. La cultura de la pobreza. Barcelona: Anagrama.

Moser, Caroline. 2006. Asset-based Approaches to Poverty Reduction in a Globalized Context. Global Economy and Development Working Paper \#01. Washington: The Brookings Institution.

Moser, Caroline. 2008. "Assets and Livelihoods: A Framework for Asset-based Social Policy", in Caroline Moser y Anis Ahmad Dani (eds.). Assets, Livelihoods and Social Policy: 43-81. Washington D.C.: World Bank.

Moser, Caroline, Pamela Sparr y James Pickett. 2007. Cutting-Edge Development Issues for INGOs. Asset Debate Paper 1. [S. 1.]: Brookings Global Economy and Development.

Mrozowicki, Adam, Valeria Pulignano y Geert Van Hootegem. 2010. "Worker Agency and Trade Union Renewal: the Case of Poland. Work, Employment and Society 24(2): 221-240.

Pemberton, Simon, Eldin Fahmy, Eileen Sutton y Karen Bell. 2016. «Navigating the Stigmatised Identities of Poverty in Austere Times: Resisting and Responding to Narratives of Personal Failure.. Critical Social Policy 36(1): 21-37.

Plummer, Ken. 1983. Documents of Life: An Introduction to the Problems and Literature of a Humanistic Method. Londres: George Allen \& Unwin.

Portes, Alejandro. 1998. "Social Capital: its Origins and Applications in Modern Sociology". American Review of Sociology 24(1): 1-24.

Putnam, Robert. 1993. Making democracy work: civic traditions in modern Italy. Princeton: Princeton University Press.

Roca, Beltran y David Florido. 2015. “Narrativas de la reconversión. Historias de vida, memoria social y acción colectiva en el astillero de Puerto Real". Revista de Dialectología y Tradiciones Populares 70(1): 11-33.

Sherraden, Michael W. 1991. Assets and the Poor. A New American Welafare Policy. Armonk: M.E. Sharpe.

Tobio, Constanza. 2005. Madres que trabajan. Dilemas y estrategias. Madrid: Cátedra.

Viveros Vigoya, Mara. 2016. "La interseccionalidad: una aproximación situada a la dominación". Debate Feminista 52: 1-17.

Wacquant, Loïc. 2000. Las cárceles de la miseria. Madrid: Alianza.

Wacquant, Loïc. 2001. "The Penalisation of Poverty and the Rise of Neo-liberalism". European Journal on Criminal Policy and Research 9: 401-412.

Fecha de recepción: 6 de noviembre de 2017

Fecha de aceptación: 23 de enero de 2018 